\title{
Fratura em linha de crescimento de cães e gatos: Revisão
}

\author{
Jéssica Caetano da Fré ${ }^{1 *}$, Sandra Márcia Tietz Marques², Marcelo Meller Alievi ${ }^{3}$
}

Discente do décimo primeiro semestre. Monografia apresentada como requisito parcial para obtenção da Graduação em Medicina Veterinária, Universidade Federal do Rio Grande do Sul, Porto Alegre, RS

${ }_{2}^{2}$ Doutora do Departamento de Patologia Clínica Veterinária, Universidade Federal do Rio Grande do Sul, Porto Alegre, RS. E-mail: smtmuni@hotmail.com

${ }^{3}$ Prof. Dr. Departamento de Medicina Animal, Universidade Federal do Rio Grande do Sul, Porto Alegre, RS E-mail: marcelo.alievi@ufrgs.br

*Autor para correspondência, E-mail: jessicadafre@hotmail.com

\begin{abstract}
RESUMO. A linha de crescimento é um tecido cartilaginoso localizado nas duas extremidades de ossos longos; são responsáveis pelo alongamento ósseo, aquisição de estrutura esponjosa outrabecular e acúmulo de massa óssea trabecular durante o desenvolvimento. A linha decrescimento é considerada menos resistente do que as estruturas que o circundam, como ossos e ligamentos, tornando a região mais suscetível a lesões. Na última década, a demanda pelo atendimento na clínica de pequenos animais se multiplicou. Proporcionalmente ao aumento de consultas gerais, é registrado o aumento de atendimento de animais com fraturas ortopédicas, das quais se sobressaem as fraturas em linha de crescimento em filhotes. Um diagnóstico rápido e tratamento apropriado são fundamentais. Compreender a anatomia e histologia do disco de crescimento é importante para determinar o efeito de lesões específicas sobre o potencial de crescimento diáfise. Este trabalho se propõe a fazer uma revisão de literatura sobre esta doença para as espécies canina e felina, abordando os aspectos da origem e histologia do osso, descrevendo e classificando as fraturas em linhas de crescimento, prevalência, diagnóstico, tratamento e prognóstico.
\end{abstract}

Palavras chave: Cirurgia, fratura, linha de crescimento, osso

\section{Fracture in growth plate in dogs and cats: Review}

\begin{abstract}
The growth plate is a cartilaginous tissue located at both ends of long bones; They are responsible for bone lengthening, acquiring of spongy or trabecular structure and trabecularbone mass accumulation during the development. The growth plate is considered less resistant than the surrounding structures, such as bones and ligaments, making the region more susceptible to injuries. In the last decade the demand for care at the clinic for small animals has multiplied. Proportionally to the increase of general consultation, it is recorded the increase of animal care with orthopedic fractures, of which stand out the growth plate fractures in puppies. A fast diagnosis and appropriate treatment are essential. Understanding the anatomy and the histology of the growth disk is important to determine the effect of specific lesions on the growth potential of the physis. This paper aims to make a literature review about this disease for the canine and feline species, covering the aspects of bone origin and histology, describing and classifying fractures in growth lines, prevalence, diagnosis, treatment and prognosis.
\end{abstract}

Keywords: growth plate, bone, fracture, surgery

\section{Introdução}

A maior parte do crescimento animal ocorre entre o $3^{\circ}$ e $6^{\circ}$ mês. O esqueleto embrionário se desenvolve a partir de um molde de cartilagem hialina que gera os centros de crescimento primário e secundário; em ossos longos, esse centro primário dará origem a diáfise óssea, e mais tarde no processo de maturação embrionária, o centro de crescimento secundário dará origem às epífises. A medida que os centros primários e secundários se aproximam, se forma o disco de 
crescimento nas duas extremidades do osso e responsável pelo alongamento ósseo, aquisição de estrutura esponjosa ou trabecular e acúmulo de massa óssea trabecular durante o desenvolvimento. Em um cão de porte médio os discos de crescimentos se fecham aproximadamente com um ano de idade, em animais de raças maiores os discos podem permanecer abertos até 18-20 meses (Von Pfeil, 2009). A grande ocorrência de lesões epifisárias femorais é devido a pouca quantidade de matriz óssea existente na região metafisária, o que a torna mais frágil em relação aos ligamentos, cápsula articular e ossos adjacentes. O resultado de uma sobrecarga na fise é uma fratura na zona hipertrófica (Kowaleski \& Barcelona, 2013).

Existem diversas formas de tratamento para fraturas epifisárias, como a utilização de pinos intramedulares (Dallabrida et al., 2005), parafusos (Knight, 1956; Hinko, 1974), placas (Alievi et al., 2007), além de métodos fechados como tala de Thomas modificada e bandagens simples (Boudrieau, 2004). A maioria dos métodos requer um segundo procedimento, o cirúrgico para a remoção dos implantes após o processo de consolidação. Portanto, esta revisão aborda fratura em disco de crescimento sob os aspectos da prevalência, diagnóstico, tratamento e prognóstico.

\section{Revisão de literatura}

Osso

Os ossos são as estruturas principais do esqueleto e juntamente com as articulações e estruturas de sustentação, são responsáveis por suportar e proteger o corpo, além de permitir a movimentação promovida pelos músculos e iniciada pelo sistema nervoso (McGavin \& Zachay, 2013). Além da função mecânica, os ossos exercem uma função químico metabólica importante, que proporcionam reservatório para a homeostase mineral (Slatter, 2007). Uma rede concentrada de vasos sanguíneos abastece não apenas o tecido ósseo, mas também a medula óssea, o periósteo e o endósteo. Traumas ou fraturas podem interromper a vascularização, podendo acarretar em morte do tecido (necrose óssea) (König \& Liebich, 2011).

Os ossos podem ser agrupados em: ossos longos, ossos curtos, ossos planos, ossos pneumáticos e ossos irregulares (König \& Liebich, 2011). Nas superfícies articulares encontramos a cartilagem articular, formada por tecido conjuntivo. Circundando o osso está uma estrutura membranosa, que leva o nome de periósteo. A trama de osso esponjoso lamelar fica debaixo da fise em uma metáfise e o osso compacto cortical circunda uma cavidade medular na região diafisária (Slatter, 2007).

Os ossos longos se caracterizam por um corpo (parte média) ou diáfise, formada a partir de uma grossa camada externa compacta de osso (substância compacta), e uma cavidade medular interna (cavum medullare). Os ossos longos apresentam duas extremidades, a epífise proximal e a epífise distal, ambas cobertas por uma fina camada de substância cortical (König \& Liebich, 2011).

O osso se forma inicialmente por uma massa mesenquimal (mesoderma) que dá origem aos tecidos esqueléticos, músculos e tendões, fáscias e vasos sanguíneos, recoberta por ectoderma que irá originar a epiderme e seus derivados (Dyce et al., 2004). Durante o desenvolvimento fetal, forma-se um esqueleto precursor de cartilagem que providencia sustentação e estabelece um formato (esqueleto primordial) para o feto durante sua etapa de crescimento (König \& Liebich, 2011) que contém um centro de calcificação de condrócitos circundados por uma fina camada de osso esponjoso, essa área é chamada de primeiro disco de calcificação (Von Pfeil, 2009). Os modelos cartilaginosos crescem principalmente, no interstício onde cada parte se expande de maneira mais ou menos uniforme, mantendo um formato geral. O próximo estágio envolve a substituição da cartilagem por tecido ósseo. $\mathrm{O}$ processo não ocorre de maneira idêntica ou síncrona em ossos diferentes para membro anterior e posterior (Dyce et al., 2004).

Os andrógenos e estrógenos desempenham um importante papel na determinação do tempo de fechamento da placa de crescimento e a castração precoce do cão resulta em atraso no fechamento da placa de crescimento com subsequente comprimento aumentado dos ossos comparados aos indivíduos intactos (McGavin \& Zachay, 2013).

A ossificação inicial compreende dois processos. Em um, o pericôndrio ao redor do terço médio da diáfise deposita osso em uma cartilagem. Esse processo de formação óssea é conhecido como ossificação intra-membranosa, por ocorrer na membrana de tecido conjuntivo. Uma bainha óssea tubular, o colar periósteo, é assim formado nas proximidades do centro da diáfise e se estende 
em direção a cada extremidade. No outro processo, a cartilagem do centro da diáfise mostra alterações degenerativas ou relacionadas com o envelhecimento; suas células se hipertrofiam, passam a ocupar lacunas (espaços) maiores na matriz e então morrem enquanto a matriz é impregnada por sais de cálcio. Mais tarde, brotos similares de pericôndrio invadem os centros das duas extremidades, estabelecendo os centros secundários ou epifisários de ossificação (Dyce et al., 2004).

A cartilagem inicial permanece apenas em duas placas, esses centros têm um significado especial, os discos de crescimento, já que são responsáveis pelo crescimento em comprimento dos ossos. As placas de crescimento são mais espessas quando o crescimento é mais rápido; conforme o crescimento torna-se mais lento, a placa torna-se fina e "fecha" (sendo substituída por osso) na maturidade do esqueleto (Dyce et al., 2004). Os ossos são tecidos extremamente vascularizados, o que ressalta sua importância metabólica. Uma rede concentrada de vasos sanguíneos abastece não apenas o tecido ósseo, mas também a medula óssea, o periósteo e o endósteo. Traumas ou fraturas podem interromper a vascularização, podendo acarretar em morte do tecido (necrose óssea) (König \& Liebich, 2011).

A vascularização dos ossos é possível por meio de uma distribuição sistemática de vasos sanguíneos. As artérias nutrícias ramificam-se das artérias maiores dos membros e penetram os ossos longos através de aberturas (foramina nutritia) na diáfise, alcançando a cavidade medular após atravessarem a camada compacta, onde se dividem em vários ramos ascendentes e descendentes que abastecem as epífises e metáfises proximais e distais. Nas epífises, os vasos formam artérias com extremidades em forma de laço que ultrapassam a epífise do osso subcondral para abastecer a zona calcificada da cartilagem da articulação. A partir da cavidade medular, os vasos sanguíneos abastecem a substancia compacta do osso através dos canais de Volkman. O osso esponjoso não apresenta vasos sanguíneos, e seu abastecimento ocorre pela difusão desde a medula óssea. O retorno venoso ocorre através do sistema axial da medula óssea (König \& Liebich, 2011).

\section{Histologia do disco de crescimento}

Os discos de crescimento são constituídos por um disco cartilaginoso que não foi penetrado pelo osso em expansão e que será responsável, de agora em diante, pelo crescimento longitudinal do osso. A cartilagem de conjugação fica entre o tecido ósseo das epífises e o da diáfise. No disco de crescimento distinguem-se cinco zonas: Zona de repouso com cartilagem hialina sem qualquer alteração morfológica; Zona de cartilagem seriada ou de proliferação, na qual os condrócitos dividem-se rapidamente e formam fileiras ou colunas paralelas de células achatadas e empilhadas no sentido longitudinal do osso; Zona de cartilagem hipertrófica, que apresenta condrócitos muito volumosos, com depósitos citoplasmáticos de glicogênio e lipídios. A matriz fica reduzida a tabiques delgados, entre as células hipertróficas e os condrócitos entram em apoptose; Zona de cartilagem calcificada na qual ocorre a mineralização dos delgados tabiques de matriz cartilaginosa e termina a apoptose dos condrócitos; Zona de ossificação, zona em que aparece tecido ósseo; os capilares sanguíneos e células osteoprogenitoras originadas do periósteo invadem as cavidades deixadas pelos condrócitos mortos; as células osteoprogenitoras se diferenciam em osteoblastos, que formam uma camada continua sobre os restos da matriz cartilaginosa calcificada e sobre esses restos de matriz cartilaginosa, os osteoblastos depositam a matriz óssea. A matriz óssea calcifica-se e aprisiona osteoblastos que se transformam em osteócitos. Desse modo formam-se as espiculas ósseas, com uma parte central de cartilagem calcificada e uma parte superficial de tecido ósseo primário (Junqueira \& Carneiro, 2013, Kowaleski \& Barcelona, 2013).

Alterações bioquímicas ocorrem dentro da zona de ossificação, em preparação para a calcificação subsequente. Dentro da zona de semeadura, calcificação provisória da matriz com fosfato de cálcio amorfo conduz a formação de cristais hidroxiapatita e calcificação subsequente. $\mathrm{O}$ disco de crescimento deriva seu fornecimento de sangue de ambos os vasos epifisários e metafisários que são os ramos terminais da artéria nutrícia. Se o fornecimento de sangue para a epífise é interrompido, necrose da camada de células germinais resulta na cessação permanente de crescimento. Perda de suprimento sanguíneo resulta em uma cessação reversível de crescimento, que é restaurada quando o fornecimento de sangue é restabelecido. Compreender a anatomia da fise é importante para determinar o efeito de lesões específicas sobre o 
seu potencial de crescimento (Kowaleski \& Barcelona, 2013).

\section{Fratura}

A transição abrupta da zona de proliferação com abundante matriz para a área de relativamente pouca matriz da zona hipertrófica resulta numa área de concentração de estresse. Assim, o resultado do excesso de forças na fise resulta numa fratura na zona hipertrófica. Desde que a zona de reserva e a zona proliferativa sejam poupados, o potencial de crescimento longitudinal está preservado (Kowaleski \& Barcelona, 2013). O aumento da espessura e densidade do osso trabecular à medida que o animal envelhece, forma uma faixa de osso sólido próximo ao disco de crescimento, que resulta em padrões de fratura diferentes. Fraturas de recém-nascidos tendem a propagar pelo osso trabecular paralelo ao disco de crescimento, em animais jovens epifisiólise, e em animais adultos (após a fusão do disco de crescimento) acontece fraturas irregulares na extensão do osso. A possibilidade de fraturas no osso trabecular adjacente deve ser considerado em recém-nascidos e animais jovens quando analisarmos e classificarmos radiografias. A ocorrência clínica mais comum de fraturas metafisária em animais jovens, e da separação da fise em animais mais velhos, é uma consequência do desenvolvimento estrutural e maturação do disco de crescimento e ossos que o circundam (Celarek et al., 2014).

\section{Classificação das fraturas}

As fraturas da linha fisária são classificadas de acordo com o sistema de classificação SalterHarris, que descreve a localização da fratura com referência à placa de crescimento, mostrado na Figura 1.

\section{Prevalência de fraturas}

Os valores de prevalência variam de acordo com o estudo, mas o fêmur é sempre o osso mais fraturado em cães e gatos, chegando a quase a metade dos casos em alguns levantamentos (Phillips, 1979, Marretta \& Schrader, 1983). No estudo de Harasen (2003), 45\% das fraturas em ossos longos eram fraturas femorais, $26 \%$ eram tibiais, $16 \%$ são fraturas de rádio e ulna, e $13 \%$ em úmero. Fraturas de côndilo do úmero são mais frequentemente vistas em filhotes de 4 a 6 meses de idade. Nesse estudo as fraturas do úmero eram relativamente raras (10\%) e $8 \%$ do total ocorreram nos côndilos ou área metafisária distal. Nas fraturas de úmero distal, o côndilo lateral é mais acometido já que se situa de forma excêntrica ao eixo do membro quando o animal está em posição, quando os membros dianteiros estão submetidos a um grande impacto, como salto ou queda, o côndilo umeral lateral é literalmente arrancado pelo impacto realizado pela cabeça do rádio. Em filhotes esse impacto resulta em uma fratura Salter-Harris tipo IV, e representam 59\% das fraturas de úmero distal (Harasen, 2003).

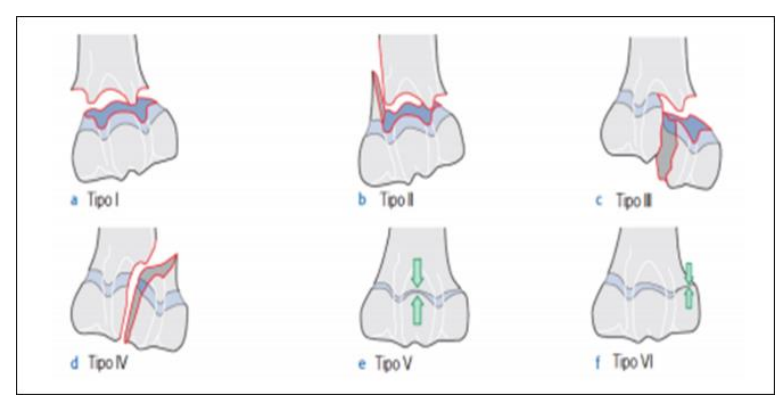

Figura 1. Representação esquemática da classificação Salter-Harris para fraturas da linha fisária. a. Tipo I - a fratura percorre a linha fisária, havendo uma separação completa da epífise e metáfise; b. Tipo II - a fratura percorre a linha fisária e uma porção da metáfise, onde um fragmento metafisário permanece ligado à epífise; c. Tipo III - a fratura ocorre parcialmente ao longo da linha fisária e epífise; d. Tipo IV - a fratura passa pela metáfise, linha fisária e atravessa a epífise; e. Tipo V a fratura ocorre por compressão da linha fisária. Inicialmente não são radiograficamente visíveis, mas, passadas algumas semanas, tornam-se evidentes quando a função da linha fisária termina, levando a alterações no crescimento; f. Tipo VI - a fratura é caracterizada por um fechamento parcial da linha fisária.

Fonte: Adaptado de Kerridge (2006).

As fraturas da epífise distal do fêmur representavam $13 \%$ do total, a maioria é tipo I e II. $\mathrm{O}$ tratamento destas fraturas normalmente envolve o uso de fios de Kirschner ou pinos intramedulares. O prognóstico para essas fraturas é bom para excelente. Quatorze por cento envolvem o terço distal do rádio e ulna, isto representa o local mais comum de fratura radial no cão e foi responsável por $85 \%$ das fraturas radiais. Estas fraturas do rádio e ulna são mais frequentemente associadas com cães de raça pequena que saltam dos braços do proprietário (Harasen, 2003). No estudo de Lucas (2001), de janeiro de 1990 a março de 1998, as fraturas foram classificadas anatomicamente com base no exame radiográfico em diferentes grupos: diafisárias distais $(35,1 \%)$, metafisárias distais $(38,6 \%)$, epifisáriasmetafisárias $\quad(14,0 \%), \quad$ separações 
epifisárias $(8,77 \%)$ e fraturas intercondilares $(1,75 \%)$. Não foi possível classificar duas fraturas $(3,38 \%)$ e dos 55 animais revisados, 41 receberam tratamento cirúrgico.

Segundo Ramadan \& Vaughan (1979), 50$55 \%$ dos cães com fraturas em ossos longos são em animais com menos de um ano, entre esses casos reportados de fraturas em ossos longos, $30 \%$ envolveu o trauma no disco de crescimento e $7 \%$ desenvolveu deformidade no crescimento. Nesse estudo com 92 cachorros com distúrbio de crescimento resultante de trauma no disco de crescimento, $75 \%$ mostrou o distúrbio da ulna ou rádio. A tíbia apresentou $4 \%$ e o fêmur $8 \%$ das deformidades apresentadas. Em um estudo de 135 cães jovens que sofreram fratura de ossos longos, cerca de um terço a um quarto das fraturas envolveu a região epifisária. Lesões Salter-Harris do tipo II foram predominantes. As epífises mais comumente envolvidas são: distal do fêmur, úmero distal, fêmur proximal, distal ulna, rádio distal, tíbia proximal e distal da tíbia (Piras et al., 2011). Do total das fraturas epifisárias, as fraturas Salter-Harris tipo I e II são as mais comuns, contando $65,5 \%$ das fraturas em pequenos animais, e fraturas tipo III e IV são $25,5 \%$ das fraturas caninas do disco de crescimento (Von Pfeil, 2009).

\section{Exame radiográfico}

A avaliação desses pacientes pelos métodos de imagem atualmente disponíveis é indispensável e bem estabelecida. Os métodos de diagnóstico por imagem fornecem informações importantes, como o tipo de fratura, sua localização e o grau de comprometimento da fise, além da presença de barra óssea. A radiografia no Brasil é a opção mais acessível, permite boa avaliação das fraturas epifisárias e deve ser realizada em duas posições (craniocaudal e latero-lateral). Outros estudos por imagem adicionais podem acrescentar informações importantes para o tratamento, como a tomografia computadorizada, útil para avaliar o alinhamento das superfícies articulares e a presença de barras ósseas. A ressonância magnética possui vantagens como a identificação de fraturas ocultas e melhor definição da extensão da fratura, além de conseguir demonstrar alterações associadas, como lesões ligamentares. Esses métodos são essenciais para tratamento e acompanhamento adequados, minimizando ou até evitando o surgimento de complicações (Yanaguizawa et al., 2008).

\section{Tratamento cirúrgico}

Na essência, os princípios da redução da fratura envolvem ser minimamente invasivos ou realizar a redução fechada para preservar o máximo possível os tecidos moles que circundam essa fratura. Em determinados casos não é possível atingir uma redução eficaz dos fragmentos na redução fechada, então para obter uma estabilidade adequada da fratura, principalmente em cães grandes é necessário realizar a redução aberta,mesmo comprometendo o suprimento sanguíneo do local. $\mathrm{O}$ acesso à fratura gera grandes danos como: rompimento da vascularização óssea, uma estabilização ineficaz e o potencial de uma contaminação bacteriana (Harasen, 2003). Logo, cada caso deve ser analisado isoladamente, considerando local de fratura, classificação, tempo de fratura, estado clínico do animal, potencial de rompimento da vascularização e de contaminação bacteriana.

Tem sido sugerido, em seres humanos e animais, que fraturas epifisárias devem ser reparadas logo que possível após a lesão. A contração muscular e fibrose fazem com que essas fraturas sejam difíceis de reduzir e seja necessária a utilização de mais força na manipulação, o que aumenta a probabilidade de dano à placa fisária durante a cirurgia (Kowaleski \& Barcelona, 2013).

Segundo Piermattei \& Flo (2009) para preservar o potencial de crescimento, não se deve fazer ponte sobre a epífise com nenhum método de fixação que impeça o crescimento do comprimento ósseo (exemplo: parafusos compressivos, placas ósseas, fios em banda de tensão, pinos rosqueados e fixadores externos). Quanto mais jovem for o animal, mais importante isso é para prevenir o distúrbio de crescimento. Os pinos de Steinmann ou fios de Kirschner lisos e de pequeno diâmetro são métodos de fixação adequada na maior parte dos casos. Os diâmetros tipicamente variam de 1 a $2 \mathrm{~mm}$ (Piermattei \& Flo, 2009). Esses pinos podem danificar a fise onde a cruzam, no entanto, eles permitem a proliferação de cartilagem para deslizar ao longo do comprimento do implante. Assim, os pinos lisos são preferidos nos casos com um potencial de crescimento restante (Kowaleski \& Barcelona, 2013). A redução aberta e fixação interna é indicada para fraturas severamente deslocadas Tipo I, II,III e IV. O tratamento precoce, a manipulação suave durante a redução e a estabilização do fragmentoe a interferência limitada com a linha de crescimento são cruciais 
para o sucesso do tratamento de lesões fisárias (Piras et al., 2011). Particularmente para fraturas tipos III e IV deve-se fazer uma seleção cuidadosa da técnica de fixação e cirurgia rápida. A manipulação cuidadosa durante a redução e fornecimento de sangue para a fise são essenciais durante a estabilização destas fraturas. Cirurgia agressiva usando forte alavancagem e tração agressiva com os instrumentos pode danificar ainda mais o osso epifisário. Para uma redução segura deve-se fazer uma leve tração da epífise através dos ligamentos ligados ao osso longo adjacente. $\mathrm{O}$ uso de implantes que promovem estabilização, mas não fixação rígida estável, é suficiente em animais imaturos devido à sua rápida cicatrização. Geralmente são usados pequenos pinos lisos de Steinmann ou fios Kirchner, colocados o mais perpendicular possível à placa epifisária, representando uma forma ideal de fixação interna. Pinos aplicados a um ângulo menor do que 45 graus causam um efeito de travamento que predispõe para o fechamento prematuro da placa de crescimento (Piras et al., $\underline{2011)}$.

A epífise nunca deve ser comprimida; portanto, deve-se evitar usar parafusos, bandas de tensão, placas e fixadores externos ao atravessar a fise. Se a utilização de tais aparelhos ortopédicos é inevitável, que deve ser removido, logo que a união é alcançada, geralmente após 3 a 4 semanas, em animais muito jovens, no máximo em 2 semanas. Parafusos compressivos colocados para reparar fraturas Tipo III e IV não representam uma preocupação pois ficam paralelos à epífise. A não remoção desses implantes no início do processo de cicatrização pode levar ao fechamento prematuro da placa de crescimento com encurtamento e/ou deformidade do membro resultante (Piras et al., 2011, Piermattei \& Flo, 2009).

O tamanho do parafuso deve ser considerado no planejamento pré-cirúrgico: raças gigantes exigirão um parafuso de $3,5 \mathrm{~mm}$ de diâmetro e até $50 \mathrm{~mm}$ de comprimento, enquanto raças de pequeno porte vão exigir parafusos 2,0 $\mathrm{mm}$ ou até $1,5 \mathrm{~mm}$ de diâmetro(Kowaleski \& Barcelona, 2013). Harasen (2003) descobriu que os fios de Kirschner não fornecem a compressão ou a estabilidade de um parafuso guia e que a migração de arame durante o período de cicatrização é comum. Os resultados finais, no entanto, são em geral satisfatórios. Em raças de pequeno porte, alguns casos de fratura condilar apresentam poucas opções de redução, já que até mesmo um parafuso de diâmetro 1,5 milímetros pode ser grande para um paciente que pode pesar pouco mais de um quilo.

Cabassu (2001) escreveu a aplicação de um implante relativamente elástico, a placa elástica veterinária, com dois parafusos nos segmentos proximal e distal, longe do local da fratura como possível, conhecido como osteossíntese por placa elástica. Usando esta técnica, 21 filhotes com idades entre 6-20 semanas foram tratados com sucesso. Em um relato de Sarrau (2007), 17 casos de fraturas de fêmur e de tíbia em cachorros foram tratados com sucesso A elasticidade do implante acoplada com a tenra idade do paciente leva à formação rápida de um grande calo periosteal nestes casos. Fatores do paciente, tais como peso corporal, idade, nível de atividade e presença de outras lesões em outros membros devem ser considerados quando se considera esta técnica. Em cães mais velhos e maiores, com espessura cortical adequada e, portanto, parafusos ósseos e placas ósseas convencionais podem ser utilizada de forma mais segura do que a fixação elástica (Kowaleski \& Barcelona, 2013).

Kim et al. (2012) indicam a utilização de pinos percutâneos nas fraturas epifisárias Salter-Harris tipo I e II,em fraturas minimamente deslocadas com uma parcela significativa de periósteo intacta, e não é possível em fraturas que não são tratados imediatamente (mais de 24-48 horas após o trauma), por causa da contração muscular e aderências de formação de calos. O periósteo intacto tem o potencial para contribuir ainda mais para a estabilidade atuando como uma banda de tensão. O primeiro princípio da redução é para minimizar o dano aplaca de crescimento. Para alcançar este objetivo, a manobra deve geralmente ser igual a $90 \%$ de tração e $10 \%$ de movimento de alavanca. A tração inicial pode aumentar ligeiramente a deformidade, então a tração deve ser mantida até a epífise ser trazida para o alinhamento; redução é completa por realinhamento da deformidade angular. Crepitação audível ou palpável da cartilagem fisária deve ser evitada, pois pode indicar dano a linha de crescimento. Para diminuir o risco de fechamento prematuro, os pinos devem ser colocados o mais perpendicular a placa fisária possível. Nessa técnica o animal apóia o membro precocemente após a cirurgia, já que são usados pinos menores e em menor quantidade e há preservação de tecidos moles. 


\section{Tratamento não cirúrgico}

A redução fechada e fixação são preferíveis quando possível, como na porção distal da tíbia, distal do rádio, e ocasionalmente na porção final do úmero. A habilidade de se realizar com sucesso a redução fechada é limitada aos casos que são vistos precocemente e apresentam deslocamento mínimo (Piermattei \& Flo, 2009). O tratamento consiste de uma combinação de alguma forma de imobilização externa, repouso e restrição de exercício, por gaiola confinamento durante 3 a 5 semanas. Coaptação após tração e redução pode produzir bons resultados. Bandagens com componente rígido necessitam ser feitas por profissional capacitado para diminuir o potencial para complicações. Dependendo da fase e a velocidade de crescimento do paciente, o molde ou tala será necessário ser verificado e mudado frequentemente, até uma vez por semana de um animal muito jovem. As taxas de complicação de coaptação externa podem ser muito elevadas em animais jovens (Piras et al., 2011).

É preciso estar atento aos problemas associados com a coaptação por tala em animais em crescimento como deformidades valga e deformidade rotacional. Imobilização da articulação do joelho deve ser evitada, particularmente em casos de fraturas do fêmur distal para evitar o risco de complicações devastadoras como contratura quadríceps e genu recurvatum. Imobilização prolongada do membro pélvico em extensão provoca coxa valga e aumento da anteversão. Infelizmente, as duas últimas condições não são reversíveis. Coaptação da articulação antebraquiocárpica normalmente provoca frouxidão ligamentar palmar do carpo e consequente hiper-extensão do carpo. Este problema é comumente visto em raças grandes e geralmente se resolve espontaneamente com o exercício controlado. A aplicação de qualquer forma de ligaduras de suporte na tentativa de corrigir a hiper-extensão é inadequada e deveria ser evitado. Acompanhamento radiográfico frequente do processo de cura é aconselhável. Logo que sinais radiográficos de consolidação clínica são visíveis, coaptação deve ser removido (Piras et al., 2011). A redução fechada e coaptação externa é preferida para fraturas Salter-Harris tipo I ou II da parte distal da tíbia, rádio ou, ocasionalmente, úmero. Uma redução fechada bem-sucedida é possível somente em casos com mínimo deslocamento e se feita nos primeiros dias. Se a manobra for realizada tardiamente pode danificar a fise pela força de cisalhamento durante a manipulação, aumentando o risco de deformidades, ou pode resultar num alinhamento inadequado dos fragmentos da fratura. A colocação da tala de coaptação em animais de crescimento pode trazer riscos, para reduzi-los se faz necessário revisar a bandagem frequentemente e considerar a remoção em 2 semanas em animais com menos de 5 meses de idade (Piras et al., 2011). Manejo conservativo das fraturas umerais geralmente tem um péssimo prognóstico já que as bandagens não conseguem neutralizar adequadamente as forças na fratura, devido ao seu local anatômico (Simpson, 2004).

\section{Cicatrização do disco de crescimento}

Segundo Fossum (2014) as fraturas ao longo do disco de crescimento tendem a cicatrizar rapidamente em razão do crescimento contínuo da cartilagem fisária e da formação de calo metafisário, devido ao não comprometimento das células em crescimento e à vascularização adjacente. Uma vez que as falhas da fratura estejam preenchidas, a ossificação endocondral normal é concluída e a função fisária continua. No entanto, se houver lesão às células em crescimento (zonas de reserva e proliferação), não ocorrerá crescimento da cartilagem fisária. Ao contrário, a ossificação endocondral toma parte, e a formação óssea nas falhas de fraturas resulta no fechamento precoce das fises. O mau alinhamento da fise fraturada (onde o osso metafisário e o epifisário estão em contato) permite a cicatrização de osso esponjoso e continuidade fisária. A ligação em ponte pode prevenir a função fisária normal. Como as fraturas fisárias frequentemente cicatrizam com a ossificação endocondral, a linha da fise é radiograficamente substituída por osso.

\section{Prognóstico}

A consolidação de fraturas em animais jovens é rápida, de 2 a 4 semanas, e depende da idade, a maior parte dos animais produz um calo exuberante independente do método de estabilização. O remodelamento é muito ativo e é completado com rapidez, com todas as evidencias de fraturas obliteradas dentro de poucas semanas. A não união é muito rara. As fraturas da epífise são acompanhadas de hemorragia considerável, rápida organização do calo e frequentemente deslocamento significativo resultante das forças musculares (Piermattei \& Flo, 2009). O prognóstico para fraturas fisárias é geralmente reservado independente da classificação SalterHarris. Em animais com potencial de crescimento 
remanescente mínimo e redução precisa da fratura, o prognóstico é bom (Kowaleski \& Barcelona, 2013). Segundo Salter (1999) o prognóstico para o crescimento após lesões fisárias não pode basear-se apenas na classificação radiográfica da fratura; deve ser considerada também a idade do animal no momento da lesão, o fornecimento de sangue para a epífise, o método de redução, se a fratura é aberta ou fechada e velocidade e força do impacto. As placas de crescimento devem ser preservadas para o crescimento normal ocorrer, de preferência, o periósteo não deve ser danificado durante a abordagem cirúrgica ou aplicação de fixação, a região cortical é fina e, portanto, o uso de parafusos de osso é inadequado. Segundo Piermattei \& Flo (2009), 5 a 10\% dos casos de fraturas em disco de crescimento vão desenvolver deformidades de crescimento, dos quais a maior parte irá necessitar de osteotomia corretiva para restabelecer a função normal. A tendência em desenvolver uma anormalidade de crescimento é mais provável em cães de raças de porte médio a grande que tem menos de cinco meses de vida no momento da lesão. As lesões Salter-Harris tipo V da fise ulnar distal tem maior probabilidade de produzir deformidade significativa que qualquer outra lesão.

\section{Complicações}

As deformidades de crescimento são causadas por uma lesão parcial ou total para a zona germinativa, por obliteração da vascularização epifisária ou metafisária ou por doenças do disco de crescimento, por exemplo, osteodistrofia hipertrófica ou retenção do núcleo cartilaginoso. Muito frequente ocorrer uma lesão adicional, especialmente lesão vascular, é causada pela redução ou fixação incorreta. Os resultados destas lesões são encurtamento do osso, os desvios axiais, incongruência das articulações adjacentes combinados com o músculo e o encurtamento do tendão. Distúrbios de crescimento de outros ossos do membro afetado também são vistos. A extensão da deformação depende da idade do animal quando ferido, o osso $\mathrm{e}$ fise afetada. A deformidade óssea na osteodistrofia hipertrófica pode ser causada por trauma mínimo para as células germinais que são muito frágeis (Prieu, 1989).

\section{Conclusões}

Entre as diversas afecções que podem acometer a placa de crescimento, as lesões traumáticas que resultam em fraturas epifisárias são as mais frequentes. Os diversos métodos de diagnóstico por imagem são indispensáveis na avaliação desses pacientes, pois fornecem dados importantes para o diagnóstico precoce e planejamento terapêutico adequado, reduzindo a possibilidade de complicações. Os princípios da redução da fratura envolvem ser minimamente invasiva ou realizar a redução fechada para preservar o máximo possível os tecidos moles que circundam essa fratura. Cada caso deve ser analisado isoladamente, considerando o local de fratura, estado clínico do animal, potencial de rompimento da vascularização e de contaminação bacteriana.

\section{Referências Bibliográficas}

Alievi, M. M., Schossler, J. E. W., Guimaraes, L. D.Oliveira, A. N. C., Traeslel, C. K. \& Ferreira, P. A. (2007). Implante ósseo cortical alógeno conservado em mel na reconstrução de falha óssea diafisária em fêmur de cães: avaliação clínica e radiográfica. Ciência Rural, 37, 450457.

Boudrieau, R. J. (2004). Miniplate reconstruction of severely comminuted maxillary fractures in two dogs. Veterinary Surgery, 33, 154-163.

Celarek, A., Fischerauer, S. F., Weinberg, A. M. \& Tschegg, E. K. 2014. Fracture patterns of the growth plate and surrounding bone in the ovine knee joint at different ages. Journal of the Mechanical Behavior of Biomedical Materials, 29, 286-294.

Cabassu, J. P. (2001). Elastic plate osteosynthesis of femoral shaft fractures in young dogs. Veterinary and Comparative Orthopaedics and Traumatology, 14, 40-45.

Dallabrida, A. L., Schossler, J. E., Aguiar, E. S. V., Amendola, G. F., Silva, J. H. S. \& Soares, J. M. D. (2005). Biomechanical analisis ex vivo of two osteosynthesis methods for transversal diaphiseal fracture in canine femur. Ciência Rural, 35, 116-120.

Dyce, K. M., Wensing, C. J. G. \& Sack, W. O. (2004). Tratado de anatomia veterinária. Elsevier Brasil, São Paulo.

Fossum, T. W. (2014). Cirurgia de pequenos animais, 4 edn. Elsevier Brasil, São Paulo.

Harasen, G. (2003). Common long bone fractures in small animal practice - part 1. The Canadian Veterinary Journal, 44, 333-334. 
Hinko, P. J. 1974. Lag screw fixation for distal femoral epiphyseal fractures. Journal of the american animal hospital association, 10, 6174.

Junqueira, L. C. \& Carneiro, J. C. (2013). Histologia Básica, 12 ed. edn. Guanabara Koogan, Rio de Janeiro.

Kerridge, R. K. (2006). Perioperative patient management. Best Practice \& Research Clinical Obstetrics \& Gynaecology, 20, 23-40.

Kim, S. E., Hudson, C. C. \& Pozzi, A. (2012). Percutaneous pinning for fracture repair in dogs and cats. Veterinary Clinics of North America: Small Animal Practice, 42, 963-974.

Knight, G. C. (1956). The use of transfixion screws for the internal fixation in small animals Veterinary record, 68, 415-421.

König, H. E. \& Liebich, H.-G. (2011). Anatomia dos Animais Domésticos. Artmed Editora.

Kowaleski, M. P. \& Barcelona, S. (2013). Management of the growth plate and juvenile long bones. Proceedings of the Southern European Veterinary Conference \& Congreso Nacional. Barcelona.

Lucas, S. S., Alievi, M. M., Cony, A. V. \& Schossler, J. E. W. (2001). Fractures of the distal femur in dogs and cats. Review of 55 cases. Revista da FZVA, 7/8, 75-83.

Marretta, S. M. \& Schrader, S. C. (1983). Physeal injuries in the dog: a review of 135 cases. Journal of the American Veterinary Medical Association, 182, 708-710.

McGavin, D. \& Zachay, J. F. (2013). Bases da patologia em veterinária. Elsevier Brasil, São Paulo.

Phillips, I. R. (1979). A survey of bone fractures in the dog and cat. Journal of Small Animal Practice, 20, 661-674.

Piermattei, B. D. L. \& Flo, G. L. (2009). Ortopedia e tratamento das fraturas dos pequenos animais, 3 ed. edn. Editora Manolo, São Paulo.
Piras, L., Cappellari, F., Peirone, B. \& Ferretti, A. (2011). Treatment of fractures of the distal radius and ulna in toy breed dogs with circular external skeletal fixation: a retrospective study. Veterinary and Comparative Orthopaedics and Traumatology, 24, 228-236.

Ramadan, R. O. \& Vaughan, L. C. (1979). Disturbance in the growth of the tibia and femur in dogs. The Veterinary Record, 104, 433-435.

Salter, R. B. (1999). Textbook of disorders and injuries of the musculoskeletal system: An introduction to orthopaedics, fractures, and joint injuries, rheumatology, metabolic bone disease, and rehabilitation. Lippincott Williams \& Wilkins.

Slatter, D. H. (2007). Manual de cirurgia de pequenos animais. Manole, São Paulo.

Sarraun, S., Meige F. \& Autefage, A. (2007). Treatment of femoral and tibial fractures in puppies by elastic plate osteosynthesis. A review of 17 cases. Veterinary and Comparative Orthopaedics and Traumatology, 20, 51- 58.

Von Pfeil, D. J. F. (2009). Orthopedic problems in the immature dog. VeterinarySpecialistsof Alaska, 1, 1-10.

Yanaguizawa, M., Taberner, G. S., Aihara, A. Y., Yamaguchi, C. K., Guimarães, M. C., Rosenfeld, A., Fernandes, J. L. \& Fernandes, A. d. R. C. (2008). Avaliação por imagem das lesões da placa de crescimento. Radiologia Brasileira, 41, 199-204.

\section{Article History:}

Received 3 august 2016

Accepted 8 September 2016

Available on line 14 October 2016

License information: This is an open-access article distributed under the terms of the Creative Commons Attribution License 4.0, which permits unrestricted use, distribution, and reproduction in any medium, provided the original work is properly cited. 